\title{
Square-Wave Voltammetry Determination of Ciprofloxacin in Pharmaceutical Formulations and Milk Using a Reduced Graphene Oxide Sensor
}

\author{
Lucas V. Faria, ${ }^{a}$ Jian F. S. Pereira, ${ }^{b}$ Gustavo C. Azevedo, ${ }^{a}$ Maria A. C. Matos, ${ }^{a}$ \\ Rodrigo A. A. Munoz ${ }^{\circledR *}, b$ and Renato C. Matos ${ }^{a}$ \\ ${ }^{a}$ Departamento de Química, Universidade Federal de Juiz de Fora, \\ 36026-900 Juiz de Fora-MG, Brazil \\ ${ }^{b}$ Instituto de Química, Universidade Federal de Uberlândia, 38400-902 Uberlândia-MG, Brazil
}

\begin{abstract}
In this paper, a simple, sensitive and precise electroanalytical method was developed using a chemically-reduced graphene-oxide (CRGO)-modified glassy carbon electrode and square wave voltammetry (SWV) for determination of ciprofloxacin in pharmaceutical formulations (tablets) and milk samples. Advantages of this sensor include a potential displacement of $100 \mathrm{mV}$ and a 5-fold current increase for the electrochemical oxidation of ciprofloxacin, which resulted in a highly sensitive sensor, when compared to unmodified electrode. The improved properties of the modified electrode are likely due to the formation of a porous surface evidenced by the change in electrode kinetics (thin-layer diffusion process). The proposed sensor is free from interference of sample matrix (pharmaceutical formulations and low/high-fat milk) avoiding cumbersome processes such as previous separations, solvent extraction, or sample filtration (samples were only diluted in Britton-Robinson buffer solution). The results by SWV showed a limit of detection of $0.21 \mu \mathrm{mol} \mathrm{L} \mathrm{L}^{-1}$ (correspondent to $0.069 \mathrm{mg} \mathrm{L}^{-1}$ ), which is lower than the ones obtained using other carbon-based electrodes, relative standard deviations lower than $12 \%$, and satisfactory recoveries in the range from 84 to $109 \%$. The results obtained were statistically similar (95\% confidence level) with those performed through high-performance liquid chromatography (HPLC).
\end{abstract}

Keywords: chemically-reduced graphene-oxide, ciprofloxacin, pharmaceutical formulations, milk, square wave voltammetry

\section{Introduction}

Ciprofloxacin (CIP) [1-cyclopropil-6-fluoro-4-oxo7-piperazin-1-ylquinoline-3-carboxilic acid] is a synthetic chemotherapeutic agent used to treat severe and lifethreatening bacterial infections. ${ }^{1,2}$ CIP has been widely used in clinical practice because of its low toxicity, wide antibacterial spectrum and low ability to cause bacterial resistance. ${ }^{3}$ It provides effective treatment for a variety of infections particularly those of the urinary tract, respiratory tract, gastrointestinal tract, skin and soft tissues. ${ }^{4}$

The use of CIP in veterinary practices is widespread not only for the therapeutic treatment of livestock, but also for the prevention and etiology of microbial diseases. ${ }^{5}$ The presence of antibiotic residues is one of the main chemical contamination in milk and dairy products. ${ }^{6}$ The milk

*e-mail: munoz@ufu.br contaminated with antibiotics is considered inappropriate for human consumption and signifies a risk for public health. Besides, there is the possibility of interference in technological production processes. ${ }^{6,7}$ Hence, the use of antibiotics in cattle was strictly regulated, for example, in the European Union the maximum residue limit of CIP in milk is $0.1 \mathrm{mg} \mathrm{L}^{-1.8}$

The literature shows different analytical methods for determination of CIP, including high-performance liquid chromatography (HPLC), ${ }^{4,7,9}$ spectrophotometry in the ultra-violet (UV) region, ${ }^{10}$ chemiluminescence, ${ }^{11}$ biosensor ${ }^{12}$ and capillary electrophoresis. ${ }^{13,14}$ Electroanalytical methods were also reported for determination of CIP employing screen-printed electrodes ${ }^{15,16}$ and multiwalled carbonnanotube modified electrodes. ${ }^{8,17,18}$ The need to include polymeric films associated with carbon nanotubes was reported for improving the selectivity of the sensor for the analysis of complex samples. ${ }^{18}$ Alternatively, laborious extraction procedures have been described for CIP 
determination in milk samples to reduce sample matrix effects and for preconcentration. ${ }^{19}$

A very explored strand in the development of electrochemical sensors is the chemical modification of the electrode surface, which provides unique characteristics to this material. Carbon materials have been widely used in electroanalysis due to some special features including low cost, wide potential window and low sensitivity to dissolved oxygen. ${ }^{20}$ Since the nobel prize in 2010, graphene has been investigated in various applications. ${ }^{21-23}$ Reduced graphene oxide (RGO) is a two-dimensional material formed of $\mathrm{sp}^{2}$ hybridized carbon atoms with a densely packed hexagonal structure and oxy-functional groups. ${ }^{24}$ The main properties of this material include excellent adsorptivity and conductivity, high strength and good flexibility for chemical modification and for this reason RGO has appeared as a relevant carbon material in the development of electrochemical sensors. ${ }^{25,26} \mathrm{In}$ recent years, the use of chemically modified electrodes with RGO dramatically increased as a result of the main advantages obtained with this material for sensing, such as gain in sensitivity and detectability compared with bare electrodes and even with other chemical modifiers, due to the electrocatalytic characteristic of graphene-based materials..$^{20,26-29}$

The aim of this work was to investigate the use of RGO in the development of a sensitive and stable electrochemical sensor for the determination of CIP in pharmaceutical formulations (tablets) and milk samples. Improved characteristics obtained with RGO allowed for the direct determination of CIP in a complex sample such as milk without a laborious sample preparation step, using square-wave voltammetry (SWV). For validation of the sensor, the samples were analyzed by high-performance liquid chromatography with UV detection (HPLC-UV).

\section{Experimental}

Reagents, solutions and samples

All aqueous solutions were prepared with deionized water with resistivity of at least $18 \mathrm{M} \Omega \mathrm{cm}$ obtained by Milli-Q purification system (Millipore, Burlington, USA). Graphene oxide (GO) was obtained from Sigma Aldrich (St. Louis, USA) and for its chemical reduction sodium borohydride (Sigma Aldrich, St. Louis, USA) was employed. CIP analytical standard was obtained from Sigma Aldrich (St. Louis, USA). All solutions were freshly prepared just before use. CIP solutions were prepared daily using $10 \mathrm{mmol} \mathrm{L}^{-1}$ acetic acid, before the experiments. Britton-Robinson (BR) buffer solutions with $\mathrm{pH}$ values adjusted in the range from 2.0 to 10.0 were used. Two pharmaceutical formulations samples (tablets) were acquired in a local drugstore while four low and high-fat bovine milk samples were purchased in local supermarkets. The excipients present in the pharmaceutical formulations samples are microcrystalline cellulose, povidone, croscarmellose sodium, silicon dioxide, magnesium stearate, copolymer of polyvinyl alcohol polyethylene glycol, macrogol and titanium dioxide. The milk samples contained sodium triphosphate, sodium bisphosphate and sodium monophosphate as stabilizing agents.

\section{Instrumentation}

The electrochemical measurements, cyclic voltammetry and SWV were performed with $\mu$ Autolab Type III potentiostat (Metrohm, Herisau, Switzerland) interfaced to a computer equipped with GPES software (version 4.9.007, Eco Chemie). The working electrode was a glassy carbon electrode (GCE) (Ø 3 mm, Metrohm, Herisau, Switzerland). $\mathrm{An} \mathrm{Ag} / \mathrm{AgCl}$ (sat) electrode and platinum wire were used as reference and auxiliary electrodes, respectively.

Raman spectra were obtained using a LabRAM HR evolution microscope (HORIBA, Kyoto, Japan) using a $532 \mathrm{~nm}$ Ar laser.

\section{Synthesis of reduced graphene oxide}

Chemically-reduced graphene-oxide (CRGO) from GO was obtained by the chemical reduction with sodium borohydride in the proportion of $1.0 \mathrm{~mL}$ of graphene oxide dispersion in water $\left(1.0 \mathrm{mg} \mathrm{mL}^{-1}\right)$ using sonication to $6.0 \mathrm{mg}$ of sodium borohydride. The formation of a black solid was verified as a result of the reaction, identified as CRGO, which was filtered, washed with deionized water and then dried for $24 \mathrm{~h}$ in oven at $100{ }^{\circ} \mathrm{C}$.

\section{Modification of the electrode with CRGO}

Prior the modification, the GCE surface was polished in alumina suspension, followed by cleaning with the aid of sonication in deionized water to remove excess of alumina. Next, an aliquot of $10 \mu \mathrm{L}$ of a dispersion of $1.0 \mathrm{mg} \mathrm{mL}^{-1}$ of CRGO in dimethylformamide was dropped over the GCE surface. The dispersion was sonicated using an ultrasonic bath for $30 \mathrm{~min}$ before the obtaining of the aliquot. After drop casting, the electrode was placed in oven at $50^{\circ} \mathrm{C}$ for $30 \mathrm{~min}$ to eliminate the solvent and then it was ready to use. 


\section{Electrochemical measurements}

\section{Preliminary study by cyclic voltammetry}

The electroactive area of bare GCE and CRGO-modified GCE was determined by cyclic voltammetry using $1.02 \mathrm{mmol} \mathrm{L}^{-1}$ potassium ferricyanide solution in $0.1 \mathrm{~mol} \mathrm{~L}{ }^{-1} \mathrm{KCl}$ scanning from +0.7 to $-0.2 \mathrm{~V}$.

The $\mathrm{pH}$ of the supporting electrolyte (from 2.0 to 10.0 ) was investigated using a $0.04 \mathrm{~mol} \mathrm{~L}^{-1} \mathrm{BR}$ buffer solution by cyclic voltammetry scanning from 0.0 to $+1.4 \mathrm{~V}$. The effect of scan rate on the electrochemical oxidation of CIP was investigated by cyclic voltammetry on bare and CRGO-modified electrode in the range between 25 and $200 \mathrm{mV} \mathrm{s}^{-1}$.

\section{SWV determination of CIP}

The SWV parameters selected for CIP determination were amplitude, frequency and potential step. A standard solution of CIP of $30 \mu \mathrm{mol} \mathrm{L^{-1 }}$ was used in these studies. The selection was performed in univariate manner based on the highest analytical response, in the ranges from 5 to $85 \mathrm{mV}$ of amplitude, 10 to $80 \mathrm{~Hz}$ of frequency and 1 to $12 \mathrm{mV}$ of step potential. The selected parameters of SWV were applied in the determination of CIP in pharmaceutical formulations and milk using the CRGO-modified GCE.

Analytical curves with concentrations ranging from 6 to $40 \mu \mathrm{mol} \mathrm{L}-1$ were prepared in BR buffer $\left(0.04 \mathrm{~mol} \mathrm{~L}^{-1}\right.$, $\mathrm{pH}$ 6.0) from a standard solution of $1000 \mu \mathrm{mol} \mathrm{L} \mathrm{L}^{-1}$ CIP.

The analysis was performed in an electrochemical cell containing $2.0 \mathrm{~mL}$ of supporting electrolyte $\left(0.04 \mathrm{~mol} \mathrm{~L}^{-1}\right.$ BR buffer solution $\mathrm{pH} 6.0$ ), and the sample volumes were $500 \mu \mathrm{L}$ for milk and $10 \mu \mathrm{L}$ for pharmaceutical formulations. Recovery tests were also performed for all the samples in order to evaluate possible sample matrix effects.

\section{Samples preparation for SWV determination}

For each analysis of pharmaceutical formulations, one tablet was powdered in a mortar and a portion of $25 \mathrm{mg}$ was weighted and dissolved in $0.04 \mathrm{~mol} \mathrm{~L}^{-1} \mathrm{BR}$ buffer solution ( $\mathrm{pH}$ 6.0) for the analysis. A filtration procedure was not necessary.

The analysis of milk samples with high and low-fat content was performed using $1.00 \mathrm{~mL}$ of sample which was transferred to a $10.00 \mathrm{~mL}$ volumetric flask followed by dilution with $0.04 \mathrm{~mol} \mathrm{~L}^{-1} \mathrm{BR}$ buffer solution ( $\mathrm{pH}$ 6.0).

\section{HPLC analysis}

High-performance liquid chromatography (HPLC) analyses were carried out in a Shimadzu LC-6AD (Kyoto, Japan) autosampler (SIL-10AF) equipped with an UV-Vis diode array detector (SPD-M20A) and a C18 column $(250 \mathrm{~mm} \times 4.60 \mathrm{~mm}, 5 \mu \mathrm{m}$, Phenomenex, Torrance, EUA). The mobile phase was composed of a mixture of $0.017 \mathrm{~mol} \mathrm{~L}^{-1}$ phosphate buffer and methanol (40:60, v/v) using the isocratic mode. The $\mathrm{C} 18$ column was used at $40{ }^{\circ} \mathrm{C}$, with a flow rate of $1.0 \mathrm{~mL} \mathrm{~min}^{-1}$, injection volume of $50 \mu \mathrm{L}$, and UV detection at the wavelength of $278 \mathrm{~nm}$. Prior HPLC analyses, the pharmaceutical formulations samples were dissolved directly in the solvent, and filtrated with syringe filters of PTFE (polytetrafluoroethylene) membrane (0.45 $\mu \mathrm{m}$ porosity, Millipore, Burlington, MA, EUA).

\section{Results and Discussion}

\section{Characterization of RGO}

Figure 1 shows the Raman spectra of GO and CRGO materials. Two main bands (D and G) are observed, the first one related to disorder or defects in the structure (at $1350 \mathrm{~cm}^{-1}$ ), and second one (at $1580 \mathrm{~cm}^{-1}$ ) related to $\mathrm{sp}^{2}$ carbon. ${ }^{30}$ After chemical reduction of GO with sodium borohydride to produce the CRGO, a decrease in the D/G ratio was verified which indicates the recovery of the $\mathrm{sp}^{2}$ carbon orientation due to the chemical reduction process that results in increase in electron conductivity. ${ }^{31}$

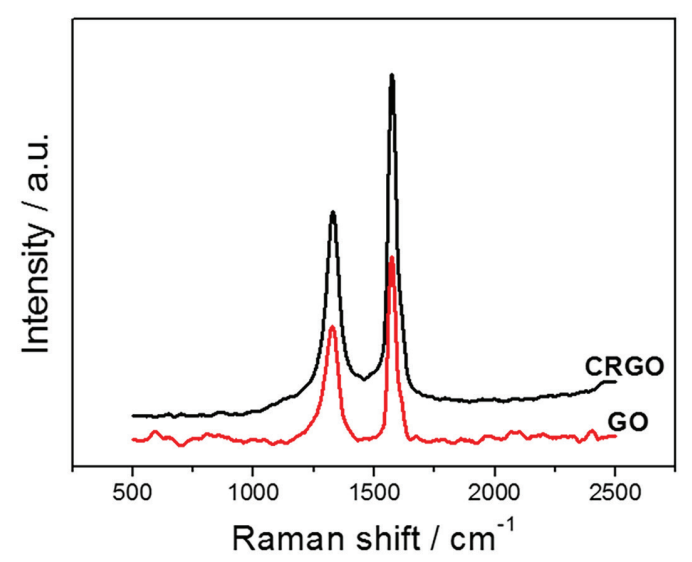

Figure 1. Raman spectrum of the CRGO and GO.

Electroactive area of unmodified and modified electrodes

The electroactive area was estimated using cyclic voltammetry (from +0.70 to $-0.20 \mathrm{~V}$ ) with an electrochemical cell containing $1.02 \mathrm{mmol} \mathrm{L}^{-1} \mathrm{~K}_{3}\left[\mathrm{Fe}(\mathrm{CN})_{6}\right]$ in $\mathrm{KCl}\left(100 \mathrm{mmol} \mathrm{L}^{-1}\right)$. Sequential measurements varying the scan rate (from 10 to $250 \mathrm{mv} \mathrm{s}^{-1}$ ) generated linear increases in the peak current. Applying the Randles Sevik equation, it was possible to determine the electroactive 

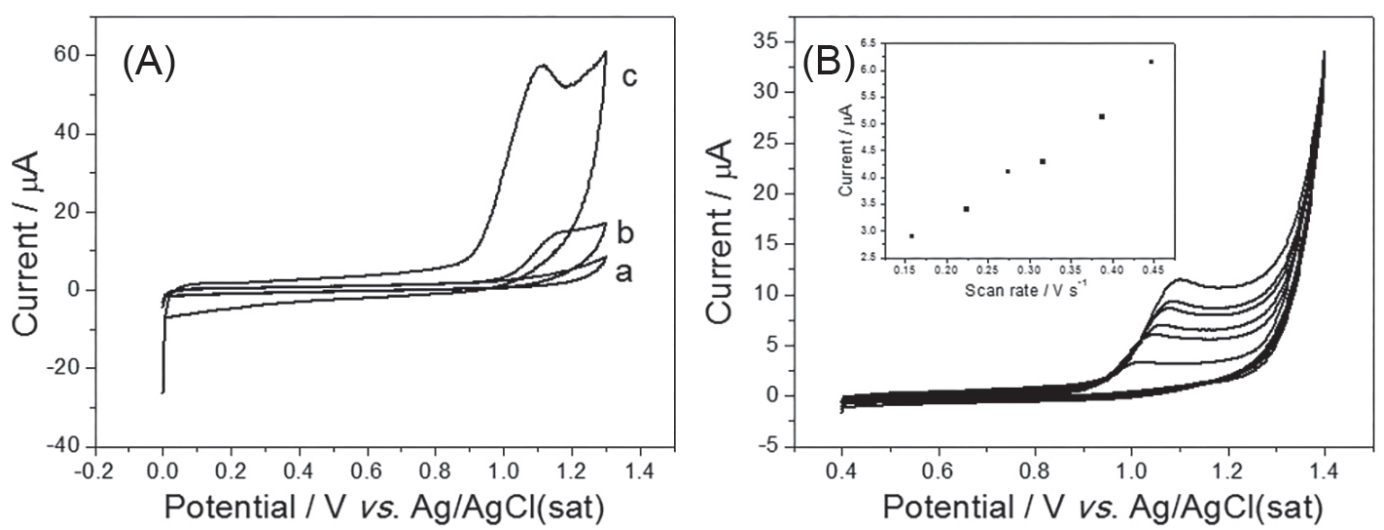

Figure 2. (A) Cyclic voltammograms of (a) GO/GCE, (b) bare GCE, (c) CRGO/GCE in CIP $500 \mu \mathrm{mol} \mathrm{L}^{-1}$ (scan rate: $100 \mathrm{mV} \mathrm{s}^{-1}$ ); (B) cyclic voltammograms of $200 \mu \mathrm{mol} \mathrm{L}{ }^{-1} \mathrm{CIP}$ at scan rate from $25-200 \mathrm{mV} \mathrm{s}^{-1}$ using CRGO. The reference electrode was $\mathrm{Ag} / \mathrm{AgCl}$ (sat), the supporting electrolyte was BR buffer $\left(0.04 \mathrm{~mol} \mathrm{~L}^{-1}, \mathrm{pH} 6.0\right)$.

areas of the unmodified and modified electrode, which were $(5.60 \pm 0.34)$ and $(7.05 \pm 0.09) \mathrm{mm}^{2}$, respectively. In this sense, it can be inferred that the modification with CRGO provided an increase of $26 \%$ in electroactive area.

\section{Electrochemical behavior of CIP on unmodified and modified electrode}

The electrochemical behavior of CIP was studied using cyclic voltammetry $(0.0$ to $+1.4 \mathrm{~V})$ and comparing both unmodified and modified electrodes. Figure $2 \mathrm{~A}$ shows the cyclic voltammograms for the oxidation processes of a CIP standard solution $\left(500 \mu \mathrm{mol} \mathrm{L}^{-1}\right)$ in BR buffer (0.04 mol L-1, $\mathrm{pH}$ 6.0). The electrochemical oxidation of CIP using GCE is irreversible with a peak at $+1.20 \mathrm{~V}$. Using the CRGO-modified electrode, an irreversible peak at $+1.10 \mathrm{~V}$ and a current gain of 5 -fold was observed, showing a possible electrocatalytic effect of CRGO. Using GO as the chemical modifier, the analytical signal was not verified, due to the insulating property of the material, which made electron transfer difficult. ${ }^{32}$

The mass transport of CIP species onto the electrode surface was evaluated by cyclic voltammetry, performing experiments in the scan rate range from 25 to $200 \mathrm{mV} \mathrm{s}^{-1}$ in the presence of CIP $\left(200 \mu \mathrm{mol} \mathrm{L}^{-1}\right)$. The plots of peak current (Ip) $v s$ scan rate showed good linearity $\left(\mathrm{R}^{2}>0.99\right)$ for CIP obtained on the modified electrode CRGO (Figure 2B), indicating that the electrochemical process was controlled by adsorption of the electroactive species onto the CRGO-modified surface. A different behavior was verified on the unmodified GCE, as a plot of square root of scan rate presented a linear behavior with the peak current which indicates that the electrochemical oxidation of CIP is controlled by diffusion of the species to the electrode.

Therefore, the modification of the GCE surface with CRGO altered the mass transport regime to a thin-layer diffusional process, which may be explained by the formation of a porous thin layer of CRGO over the electrode surface that may confine the CIP species within the CRGO film. A similar result was already verified in the literature for CRGO-modified electrodes ${ }^{26}$ as well as carbon-nanotube modified electrodes ${ }^{17,33,34}$ and carbon black-modified electrodes. ${ }^{35}$

In the study of mass transport on the modified electrode, the shift of the peak potential (Ep) as the scan rate (v) varied was clearly verified, obtaining a linear relation between Ep and $\log \mathrm{v}$ (Figure 3).

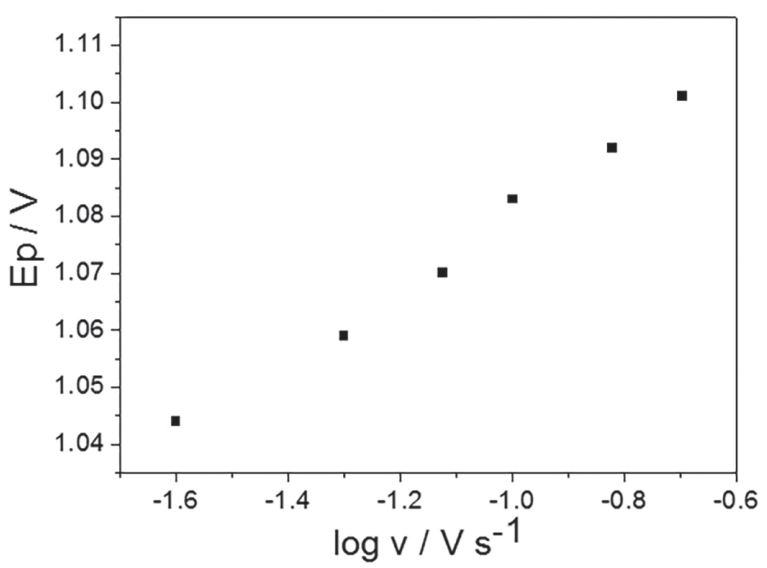

Figure 3. Study of Ep $\times \log \mathrm{v}$ of the oxidation process of the CIP using $200.0 \mu \mathrm{mol} \mathrm{L}{ }^{-1}$, scan rate from $25-200 \mathrm{mV} \mathrm{s}^{-1}$ and CRGO electrode.

From the linear adjustment, equation 1 was obtained:

$\mathrm{Ep}(\mathrm{V})=1.145+0.064 \log \mathrm{v}\left(\mathrm{Vs}^{-1}\right)\left(\mathrm{R}^{2}=0.987\right)$

which according to Laviron ${ }^{36}$ can be described as follows (equation 2):

$\mathrm{Ep}(\mathrm{V})=\mathrm{A}+\frac{2.303 \mathrm{RT}}{(1-\alpha) n \mathrm{nF}} \log \mathrm{V}$ 

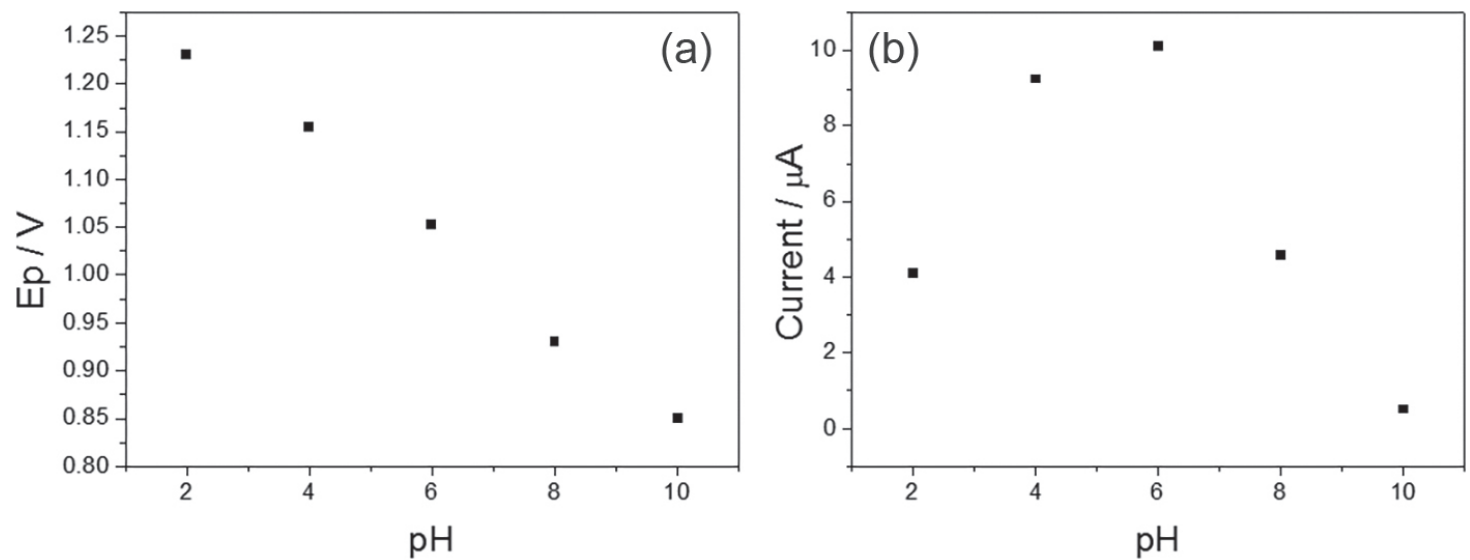

Figure 4. (a) Study of $\mathrm{Ep} \times \mathrm{pH}$ and (b) $\mathrm{Ip} \times \mathrm{pH}$ on the oxidation process, in the $\mathrm{pH}$ range from 2 to 10 , using $200 \mu$ mol $\mathrm{L}^{-1}$ of $\mathrm{CIP}_{\text {and }} \mathrm{CRGO}$ modified electrode.

where A is a constant related to the formal electrode potential (E0) and standard rate constant at E0; $\alpha$ is the transfer coefficient that characterizes the effect of electrochemical potential on activation energy of an electrochemical reaction; $\mathrm{n}$ is the number of electrons involved in the rate-controlling step; $\mathrm{R}, \mathrm{T}$, and $\mathrm{F}$ are the gas constant, temperature and Faraday constants, respectively.

According to the slope of the linear adjustment, the calculated number of electrons was $1.84(\alpha=0.5)$, suggesting that the electrochemical oxidation of CIP involved two electrons.

Preliminary tests employing cyclic voltammetry and the CRGO-modified electrode showed that the electrochemical process involving CIP is $\mathrm{pH}$ dependent. The effect of $\mathrm{pH}$ on the oxidation of CIP $\left(200 \mu \mathrm{mol} \mathrm{L} \mathrm{L}^{-1}\right)$ was investigated in a $\mathrm{pH}$ range between 2.00 and 10.00 using BR buffer solutions. The results in Figure 4 shows the investigation of potential (a) and current peak (b) as a function of five different $\mathrm{pH}$ values using the CRGO-modified electrode. It is observed that in values of $\mathrm{pH} 6.0,8.0$ and 10.0 there is a displacement of oxidation peak to more cathodic potentials. However, higher analytical signal was observed in BR buffer solution of $\mathrm{pH} 6.0$, which was thus selected for further studies involving the determination of CIP.

Figure 4a shows the linear relationship between Ep and $\mathrm{pH}$. The slope of the linear adjustment $(\mathrm{Ep} \times \mathrm{pH})$ was equal to $50 \mathrm{mV} \mathrm{pH}^{-1}$, which is close to the theoretical value of $59 \mathrm{mV} \mathrm{pH}^{-1}$. Therefore the number of protons involved in the oxidation of CIP is equal to the number of electrons. Figure 5 shows the oxidation mechanism of CIP, which is consistent with other studies in the literature. ${ }^{15}$

\section{SWV determination of CIP}

\section{Selection of the instrumental parameters}

The SWV technique was selected due to higher

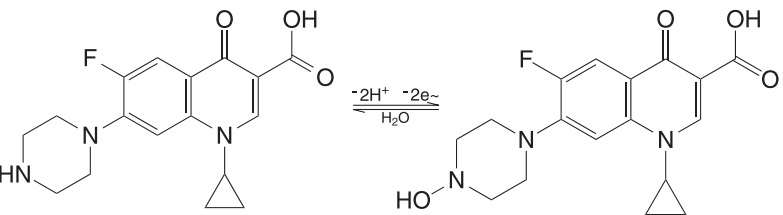

Figure 5. Proposed reaction for the electrochemical oxidation of CIP.

sensitivity and speed. The selection of the SWV parameters (amplitude, step and frequency) were based on the highest analytical signal of CIP and precision. The studied ranges were $5-85 \mathrm{mV}$ of amplitude, $1-10 \mathrm{mV}$ of step and $10-80 \mathrm{~Hz}$ of frequency and the values selected for further SWV determination of CIP were $35 \mathrm{mV}, 10 \mathrm{mV}$ and $40 \mathrm{~Hz}$, respectively, which resulted in the scan rate value of $400 \mathrm{mV} \mathrm{s}^{-1}$.

Figures of merit of the proposed sensor for CIP determination in pharmaceutical formulations and milk samples

Using the selected SWV parameters, a linear relationship between peak current and CIP concentration $\left(R^{2}=0.991\right)$ was obtained in a range of 6 and $40 \mu \mathrm{mol} \mathrm{L}^{-1}$ (Figure 6). The limit of detection (LOD) and quantification (LOQ) values were obtained from the standard deviation of blank and the slope of the analytical curve. The LOD and LOQ values were calculated as 0.21 and $0.70 \mu \mathrm{mol} \mathrm{L} \mathrm{L}^{-1}$, respectively. The repeatability and accuracy of the developed method was verified by triplicate analyses and recovery tests were performed.

The LOD of the sensor $0.21 \mu \mathrm{mol} \mathrm{L}^{-1}$ (corresponds to $0.069 \mathrm{mg} \mathrm{L}^{-1}$ ) is lower than the maximum level of CIP allowed in milk $\left(0.1 \mathrm{mg} \mathrm{L}^{-1}\right)$. In this sense, the sensor showed adequate detectability regarding the legislation for CIP content in milk samples.

An important characteristic observed for the modified electrode was its stability of at least 1 day under intense use in the presence of CIP standard. Electrode surface modification 


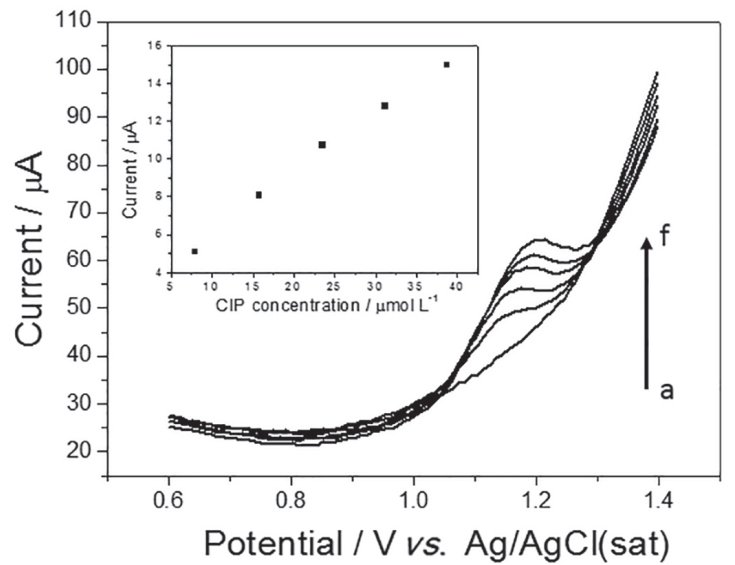

Figure 6. Analytical curve of CIP in the range of 6-40 $\mu \mathrm{mol} \mathrm{L}^{-1}$, (a) BR buffer (pH 6.0, $0.04 \mathrm{~mol} \mathrm{~L}^{-1}$ ), (f) $40 \mu \mathrm{mol} \mathrm{L}^{-1}$ of CIP. The inset presents the respective calibration plot.

studies $(\mathrm{n}=10)$ were performed and it was observed that for a fixed CIP concentration of $13 \mu \mathrm{mol} \mathrm{L}^{-1}$ using SWV, the relative standard deviation of the current measurement was $7 \%$. Thus, a very repetitive signal was maintained proving the reproducible electrode modification with CRGO.

The developed sensor was compared to other sensors for the determination of CIP reported in the literature (Table 1). The CRGO-modified electrode presented improved detectability in comparison to BDD and most MWCNTmodified electrodes exception to the Nafion (Nafion, polymeric anion exchange modified electrode) and to the electrochemical impendance spectroscopy (EIS) detection, which requires a longer time for a single measurement. Moreover, the proposed sensor was satisfactory applied to milk and drug samples.

Initially, two pharmaceutical formulations with a nominal CIP mass of $500 \mathrm{mg}$ were analyzed. Table 2 shows the obtained mass, recovery values and comparison with HPLC.
The results obtained by the proposed method were in agreement with those obtained by HPLC. At the 95\% confidence level, the calculated t-test values were smaller than the critical value (12.70), which indicates that there were no significant differences between the results.

The mass values obtained for CIP in the pharmaceutical formulations samples were in agreement with the nominal mass $(500 \mathrm{mg})$, the relative standard deviations were below $12 \%$ and the recoveries were satisfactory, showing that the method was precise and accurate.

The CIP concentration in all milk samples was below the limit of detection. In this sense, to evaluate the accuracy of the developed method, all samples were spiked with $500 \mu \mathrm{mol} \mathrm{L}{ }^{-1}$ of CIP, which corresponded to $10 \mu \mathrm{mol} \mathrm{L}-1$ of CIP in the electrochemical cell. The milk samples were only diluted in supporting electrolyte before analysis. Figure 7 shows the voltammogram obtained for the analysis of high-fat milk 1 and Table 3 shows the obtained results.

It can be seen in Table 2 that the recovery values were satisfactory (84-109\%), and thus it is noticed that constituents of milk samples did not interfere in the analysis. The relative standard deviations were lower than $12 \%$, values that are acceptable considering the concentration level $\left(10-20 \mu \mathrm{mol} \mathrm{L} \mathrm{L}^{-1}\right)$ used in the electrochemical cell. Therefore, the proposed graphene-based sensor is able to monitor CIP after a simple dilution of milk samples not requiring a laborious extraction procedure or an additional polymeric film to maintain the electroactivity of the sensor. ${ }^{18,19}$

Interference test with other antibiotics (chloramphenicol, amoxicillin, tetracycline, sulfachlorpyridazine) also used by veterinary medicine were not performed. However, it has been verified through literature studies using carbon-based sensors that these antibiotics respond at other potential ranges. ${ }^{41-44}$

Table 1. Comparison of electrochemical sensors for determination of ciprofloxacin

\begin{tabular}{|c|c|c|c|c|c|}
\hline Sensor & Method & Potential / V & $\mathrm{LOD} /(\mu \mathrm{mol} \mathrm{L}-1)$ & Samples & Reference \\
\hline MWCNT/GCE & AMP & 0.98 & 6.00 & urine and serum & 17 \\
\hline Nafion/MWCNT/BDD & DPV & 1.40 & 0.005 & wastewater & 18 \\
\hline BDD & DPV & 1.20 & 2.46 & urine & 37 \\
\hline MWCNT/Graphite & AMP & 1.20 & 5.90 & n. m. & 38 \\
\hline C-SPE & AMP & 1.20 & 0.10 & drugs & 16 \\
\hline MWCNT/GCE & LSV & 0.90 & 0.90 & urine, plasma and drugs & 39 \\
\hline MWCNT/ $/ \mathrm{V}_{2} \mathrm{O}_{5} /$ chitosan & EIS & - & 0.0015 & milk & 8 \\
\hline HMDE & DPV & -1.30 & 0.07 & urine and drugs & 40 \\
\hline CRGO/GCE & SWV & 1.10 & 0.21 & drugs and milk & this work \\
\hline
\end{tabular}

MWCNT: multiwalled carbon nanotube; GCE: glassy carbon electrode; BDD: boron-doped diamond; C-SPE: carbon screen-printed electrode; HMDE: hanging mercury drop electrode; CRGO: chemically-reduced graphene-oxide; AMP: amperometric detection; DPV: differential-pulse voltammetry; SWV: square-wave voltammetry; LSV: linear-sweep voltammetry; EIS: electrochemical impendance spectroscopy; LOD: limit of detection; n. m.: not mentioned. 
Table 2. Results obtained by analysis of CIP in pharmaceutical formulations

\begin{tabular}{|c|c|c|c|}
\hline \multirow[b]{2}{*}{ Sample } & \multicolumn{2}{|c|}{ Proposed sensor } & \multirow{2}{*}{$\begin{array}{c}\text { HPLC } \\
\text { Mass / } \\
\text { (mg per tablet) }\end{array}$} \\
\hline & $\begin{array}{c}\text { Mass / } \\
\text { (mg per tablet) }\end{array}$ & Recovery / \% & \\
\hline A & $505 \pm 34$ & $102 \pm 11$ & $580 \pm 25$ \\
\hline B & $496 \pm 36$ & $97 \pm 12$ & $464 \pm 20$ \\
\hline
\end{tabular}

HPLC: high-performance liquid chromatography.

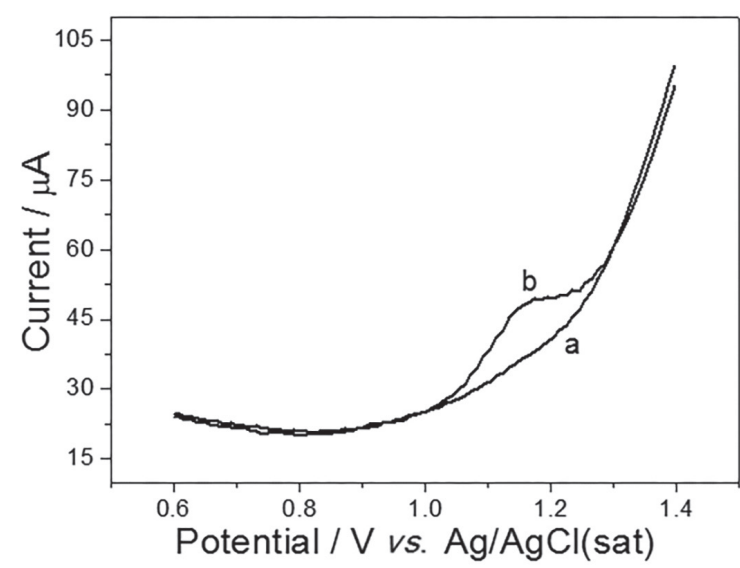

Figure 7. Voltammogram obtained for analysis of high-fat milk 1 sample (a), and the high-fat milk 1 sample spiked with $500 \mu \mathrm{mol} \mathrm{L}^{-1}$ of CIP (b).

Table 3. Recovery values obtained in high and low-fat milk samples

\begin{tabular}{lccc}
\hline \multirow{2}{*}{ Sample } & \multicolumn{3}{c}{ Ciprofloxacin } \\
\cline { 2 - 4 } & $\begin{array}{c}\text { Added / } \\
(\mu \mathrm{mol} \mathrm{L})^{-1}\end{array}$ & $\begin{array}{c}\text { Found / } \\
\left(\mu \mathrm{mol} \mathrm{L}{ }^{-1}\right)\end{array}$ & Recovery / \% \\
\hline High-fat 1 & 500 & $422 \pm 42$ & $84 \pm 8$ \\
High-fat 2 & 500 & $473 \pm 52$ & $95 \pm 11$ \\
Low-fat 1 & 500 & $448 \pm 27$ & $90 \pm 5$ \\
Low-fat 2 & 500 & $533 \pm 66$ & $109 \pm 13$ \\
\hline
\end{tabular}

\section{Conclusions}

In the present work, an electrochemical sensor (CRGO-modified electrode) was developed from the chemical reduction of graphene oxide, which conferred potential displacement and considerable gain of analytical signal (5-fold) to CIP detection. The proposed method using SWV and the CRGO-modified GCE was optimized and applied for the determination of CIP in pharmaceutical formulations and milk samples, with adequate detectability $\left(\mathrm{LOD}=0.21 \mu \mathrm{mol} \mathrm{L}{ }^{-1}, 0.069 \mathrm{mg} \mathrm{L}^{-1}\right)$, precision $(\mathrm{RSD}<12 \%)$ and acceptable accuracy (recovery in the range of 84 and $109 \%$ ). The analytical characteristics of the proposed sensor are superior in comparison with the ones obtained with other carbon materials previously reported in the literature.
The concentrations of CIP in the milk samples were below the limit of detection, and the values determined in the pharmaceutical formulations ranged from 496 to $505 \mathrm{mg}$, which was consistent with the HPLC results and label values of the commercial drugs. In addition, the electrochemical method did not require time-consuming sample handling (simple dilution) or expensive instrumentation.

\section{Acknowledgments}

This research was supported by FAPEMIG (Research Support Foundation of the State of Minas Gerais) (process: APQ-02010-16), CNPq (National Council for Scientific and Technological Development, process: INCTBio 465389/2014-7 and 307271/2017-0), CAPES (Coordination for the Improvement of Higher Education Personnel, financial code 001) and PROPESQ/UFJF.

\section{References}

1. Pulgarin, J. A. M.; Molina, A. A.; Boras, N.; Anal. Methods 2012, 4, 3413.

2. Montes, R. H. O.; Marra, M. C.; Rodrigues, M. M.; Richter, E. M.; Muñoz, R. A. A.; Electroanalysis 2014, 26, 432.

3. Anacleto, S. S.; Borges, M. M. C.; de Oliveira, H. L.; Vicente, A. R.; Figueiredo, E. C.; de Oliveira, M. A. L; Borges, B. J. P.; de Oliveira, M. A.; Borges, W. S.; Borges, K. B.; J. Pharm. Anal. 2018, 8, 168.

4. Vella, J.; Busuttil, F.; Bartolo, N. S.; Sammut, C.; Ferrito, V.; Serracino-Inglott, A.; Azzopardi, L. M.; LaFerla, G.; J. Chromatogr. B: Biomed. Sci. Appl. 2015, 989, 80.

5. Kalunke, R. M.; Grasso, G.; D’Ovidio, R.; Dragone, R.; Frazzoli, C.; Microchem. J. 2018, 136, 128.

6. Maluf, R. S.; Ribeiro, A.; SaBio - Revista de Saúde e Biologia 2012, 7, 30 .

7. Idowu, O. R.; Peggins, J. O.; J. Pharm. Biomed. Anal. 2004, $35,143$.

8. Hu, X.; Goud, K. Y.; Kumar, V. S.; Catanante, G.; Li, Z.; Zhu, Z.; Marty, J. L.; Sens. Actuators, B 2018, 268, 278.

9. Szerkus, O.; Jacyna, J.; Gibas, A.; Sieczkowski, M.; Siluk, D.; Matuszewski, M.; Kaliszan, R.; Markuszewski, M. J.; J. Pharm. Biomed. Anal. 2017, 132, 173.

10. Palamy, S.; Ruengsitagoon, W.; Spectrochim. Acta, Part A 2018, 190, 129.

11. Vakh, C.; Pochivalov, A.; Koronkiewicz, S.; Kalinowski, S.; Postnov, V.; Bulatov, A.; Food Chem. 2019, 270, 10.

12. Gil, E. S.; Melo, G. R.; Braz. J. Pharm. Sci. 2010, 46, 375.

13. Bannefeld, K. H.; Stass, H.; Blaschke, G.; J. Chromatogr. B: Biomed. Sci. Appl. 1997, 692, 453.

14. Michalska, K.; Pajchel, G.; Tyski, S.; J. Chromatogr. A 2004, 1051, 267. 
15. Reddy, K. R.; Brahman, P. K.; Suresh, L.; Measurement 2018, $127,175$.

16. Stefano, J. S.; Cordeiro, D. S.; Marra, M. C.; Richter, E. M.; Munoz, R. A. A.; Electroanalysis 2015, 28, 350.

17. Fotouhi, L.; Alahyari, M.; Colloids Surf., B 2010, 81, 110.

18. Gayen, P.; Chaplin, B. P.; ACS Appl. Mater. Interfaces 2016, 8 , 1615.

19. Silva,W. P.; Oliveira, L. H.; Santos, A. L; Souza, V. F.; Trindade, M. A. G.; Food Chem. 2018, 250, 7.

20. McCreery, R. L.; Chem. Rev. 2008, 108, 2646.

21. Wang, C.-P.; Chou, C.-P.; Chang, T.-L.; Chou, C.-Y.; Microelectron. Eng. 2018, 189, 69.

22. Mahmoudi, T.; Wang, Y.; Hahn, Y.-B.; Nano Energy 2018, 47, 51 .

23. Justino, C. I. L.; Gomes, A. R.; Freitas, A. C.; Duarte, A. C.; Rocha-Santos, T. A. P.; TrAC, Trends in Analytical Chemistry 2017, 91, 53.

24. Geim, A. K.; Science 2009, 324, 1530.

25. Wang, Z.; Li, L.; Liu, E.; Thin Solid Films 2013, 544, 362.

26. Rocha, D. P.; Dornellas, R. M.; Cardoso, R. M.; Narcisio, L. C. D.; Silva, M. N. T.; Nossol, E.; Richter, E. M.; Munoz, R. A. A.; Sens. Actuators, B 2018, 254, 701.

27. Pruneanu, S.; Biris, A. R.; Pogacean, F.; Socaci, C.; Coros, M.; Rosu, M. C.; Watanabe, F.; Biris, A. S.; Electrochim. Acta 2015, 154, 197.

28. Li, W.; Yang, Y. J.; J. Solid State Electrochem. 2014, 18, 1621.

29. Cesarino, I.; Simões, R. P.; Lavarda, F. C.; Batagin-Neto, A.; Electrochim. Acta 2016, 192, 8.

30. Ambrosi, A. Pumera, M.; Chem. - Eur. J. 2015, 22, 153.
31. Yigit, A.; Yardim, Y.; Çelebi, M.; Levent, A.; Senturk, Z.; Talanta 2016, 158, 21.

32. Dreyer, D. R.; Park, S.; Bielawski, C. W.; Ruoff, R. S. F.; Chem. Soc. Rev. 2010, 39, 228.

33. Sims, M. J.; Ress, N. V.; Dickinson, E. J.; Compton, R. G.; Sens. Actuators, B 2010, 144, 158.

34. Montes, R. H. O.; Stefano, J. S.; Richter, E. M.; Munoz, R. A. A.; Electroanalysis 2014, 26, 1449.

35. dos Santos, W. T. P.; Amin, H. M. A.; Comptom, R. G.; Sens. Actuators, B 2019, 279, 433.

36. Laviron, E.; J. Electroanal. Chem. 1979, 101, 19.

37. Garbellini, G. S.; Rocha-Filho, R. C.; Fatibello-Filho, O.; Anal. Methods 2015, 7, 3411.

38. Silva, L. A. J.; Stefano, J. S.; Cardoso, R. M.; Prado, N. S.; Soares, P. H. T.; Nossol, E.; Munoz, R. A. A.; Angnes, L.; Richter, E. M.; J. Electroanal. Chem. 2019, 833, 560.

39. Ensafi, A. A.; Taei, M.; Khaymian, T.; Hasanpour, F.; Anal. Sci. 2010, 26, 803.

40. Al-Ghamdi, A. F.; Bani-Yassen, A. D.; Russ. J. Electrochem. 2014, 50, 355.

41. Kor, K.; Zarei, K.; J. Electroanal. Chem. 2014, 733, 39.

42. Guo, G.; Zhuo, F.; Xiao, F.; Zeng, B.; Int. J. Electrochem. Sci. 2009, 4, 1365.

43. Rezaei, D.; Damiri, S.; Electroanalysis 2009, 21, 1577.

44. Aleixo, H.; Okumura, L. L.; Gurgel, A. F. S. S.; Diniz, J. A.; Anal. Methods 2019, 11, 1743.

Submitted: February 23, 2019

Published online: May 22, 2019 